\title{
Clinical Wear Assessment of Composite Restorations Using a Digital Optical Surface Profilometry - A Retrospective Study
}

\author{
Kavalipurapu Venkata Teja ${ }^{1}$, Sindhu Ramesh ${ }^{2}$ \\ ${ }^{1}$ Department of Conservative \& Endodontics, Saveetha Institute of Medical and Technical Sciences, Saveetha \\ Dental Collage, Chennai, Tamil Nadu, India. ${ }^{2}$ Department of Conservative \& Endodontics, Saveetha Institute \\ of Medical and Technical Sciences, Saveetha Dental Collage, Chennai, Tamil Nadu, India.
}

\section{ABSTRACT}

\section{BACKGROUND}

Dental composites form the main stay in majority of the restorative procedures due to their aesthetic properties and adhesive technology. The major disadvantage with these materials is that they have less abrasion resistance and they wear on clinical service. The aim of this study was to evaluate the wear resistance of mandibular molar class- 1 composite restored teeth at different intervals of time.

\section{METHODS}

In this retrospective pilot study, thirty patients were randomly selected with mandibular first and second molars restored with class- 1 composite restorations and were grouped according to the retrospective clinical duration of the teeth restored as 1-3 years, 3-5 years and 5-7 years. High resolution images of these restorations were captured using DSLR with macro lens attached and assessed for surface irregularities and the clinical duration of the restoration was recorded. The images were magnified using NIH-IMAGE J and processed in Adobe Photoshop and digital optical surface profilometry was used to measure the irregularities formed on the surface of the restoration.

\section{RESULTS}

There was a significant increase in the mean, maximum and minimum diameter of craters and notches formed between the three groups $(\mathrm{p}<0.05)$. But there was no statistically significant difference that was seen with the area of tooth assessed, length and angle of craters formed ( $p>0.05)$.

\section{CONCLUSIONS}

Wear of the restorations increased on increased clinical duration and varied according to the dietary habits of the patients.

\section{KEY WORDS}

Composite, Dental, Molars, Optical Surface Profilometry, Restoration
Corresponding Author: Dr. Sindhu Ramesh.

Department of Conservative \& Endodontics, Saveetha Institute of Medical and Technical Sciences, Saveetha Dental Collage, Chennai, Tamil Nadu, India.

E-mail:dr.sinsushil@gmail.com

DOI: $10.14260 / \mathrm{jemds} / 2020 / 634$

How to Cite This Article:

Teja KV, Ramesh S. Clinical wear assessment of composite restorations using a digital optical surface profilometry - a retrospective study. J Evolution Med Dent Sci 2020;9(39):2898-2902, DOI: $10.14260 /$ jemds/2020/634

Submission 11-06-2020,

Peer Review 14-08-2020,

Acceptance 20-08-2020,

Published 28-09-2020.

Copyright (c) 2020 Kavalipurapu Venkata Teja et al. This is an open access article distributed under Creative Commons Attribution License [Attribution 4.0 International (CC BY 4.0)] 


\section{BACKGROUND}

Operative dentistry is a speciality which mainly deals with the replacement of the diseased tooth structure with a biocompatible material. ${ }^{1}$ From several decades, interest towards the usage of aesthetic tooth colour adhesive restorative materials increased drastically. ${ }^{2}$ Introduction to composites as restorative materials lead to dramatic change in clinical applications and quality of care delivered. ${ }^{3}$ Although composite is proven to be best in aesthetics, there are several drawbacks which are observed on long term clinical evaluation. ${ }^{4}$ Most of the patients report with discolouration and the debonding of restorations especially when not adequately isolated during the procedure. So, composites are more technique sensitive and require strict rubber dam isolation, for the long term success. Specifically composites are resin based materials which polymerise on photoactivation. So, during the polymerisation process, the complete conversion might not occur, leading to the unpolymerised resin and failure of restoration. There are reports claiming that the unpolymerised monomer is released in due course leading the failure of restoration. The main drawback of resin-based composites as restorative materials is the decreased wear resistance and lacking anti-carcinogenicity. 3,4

After introduction of tooth coloured aesthetic restorations, the patient's aesthetic demands increased drastically. Although amalgam had a better performance on long term evaluation, it lacked the property of aesthetics and adhesive nature to tooth surface. So, composites replaced completely the amalgam and other non-aesthetic restorations. But the main factor that varies in clinical judgement is the occlusal calibrations and the forces acting on a particular restoration. When anterior restorations are considered, shear and lateral stresses ante more prevalent as compared to compressive forces. But, for a composite serving for the posterior areas, especially the areas under high occlusal loads, the compressive and tensile loads exceed the physical constraints. So, the major concern with composites when used as posterior restorations is the decreased wear resistance, leading to the failure of the restorations. Hence, improved long term success of composites is based on the wear resistance of the material in the oral cavity during its clinical service. ${ }^{5}$

Although several methods like, tooth wear simulators and standard tribometers like pin-on-disc, reciprocating devices are used, the best method is to evaluate the long-term clinical performance. ${ }^{6}$ Hence the optical method is feasible. ${ }^{7}$ Development in the properties of the materials and technical approaches are the two essential factors developed during recent decades, for the improvement in the clinical performance of composite restorations. ${ }^{8}$ Studies state that, composites exhibit polymerisation shrinkage, which is a resultant of the polymerisation stress induced the process. So, this causes the marginal gaps and lead to the microleakage and failure of restoration. So, one frequent reason for the replacement of restorations is the leakage especially with the proximal restorations. The success of any restorative material is assessed by its longevity and its biocompatibility in the oral environment. 9 So, material of choice of restoration should satisfy the ideal requirement as mentioned. Especially for a posterior restoration, various above mentioned factors play a role to decide the long term success of the treatment. Hence, the present study was aimed at doing a retrospective evaluation of the wear resistance of thirty teeth restored with class- 1 composite restorations at different intervals of time.

\section{METHODS}

Ethical approval for the present study was obtained from the institutional review board. SRB / 2018 / 98. Informed consent was obtained from the patients, prior to intervention. Present study is a retrospective study. Prior to the allocation of these thirty patients, screening was carried out for around 350 patients. Simple random method was followed during the screening of the patients. Prior to the including the patients into specific sample, the history and the chief complaint were obtained. Once the required patients with specific inclusion and exclusion criteria were selected, out of which 200 patients were randomly selected with mandibular first and second molars, restored with class- 1 composite restorations and finally thirty patients were grouped according to the retrospective clinical duration of the teeth restored as 1-3 years, 3-5 years and 5-7 years. Three different operators were involved in the entire screening process for the inclusion of patients into the study. Finally the grouping of thirty patients into respective groups was not by chance but rather by specific screening by the operators involved in the study. The clinical and diet history of the patient were recorded.

The sample size was determined using G power 3.1 version. This was conducted as a pilot study, where estimated power was adjusted to $95 \%$ with $5 \%$ marginal error. The minimal sample size estimated was 6 per each group. To compensate the loss of follow-up, the sample size was increased to 10 per each group.

Inclusion criteria were - patients aged 18-45 years. Mandibular first and second molars restored with class-1 composite restorations. Exclusion criteria were patients above 45 years of age and below 18 years of age, Patients with history of adverse habits like bruxism and patients with abnormal occlusion. High resolution images of the teeth were captured using Digital Single-Lens Reflex (DSLR) Camera with macro lens attached; these images were enlarged in NIH IMAGE-J software and processed in Adobe Photoshop. Craters formed on the surface of the restoration were measured using scale present on the image as a standard. The mean diameter, angle and the length of these craters were measured. Highest measurements were taken from a single tooth of entire restoration and the mean was calculated. These measurements were done using digital optical surface profilometry.

All measurements were done in microns and statistical analysis was performed. The area of the tooth surface was measured for all the teeth, sum of the maximum and minimum values was obtained and the mean diameter, angle and length of the crater were calculated.

\section{Statistical Analysis}

Data obtained from the study was assessed using IBM. SPSS statistics software 23.0 version and analysed with a significance level established at $(\mathrm{p}<0.05)$. Mean and standard deviations on area of the tooth assessed, angle, length, mean, minimum and maximum diameters of crater and notches for each group was calculated and analysed using unpaired T-test. 
For multivariate analysis ANOVA and Post-hoc tests were used for multiple comparisons.

\section{RESULTS}

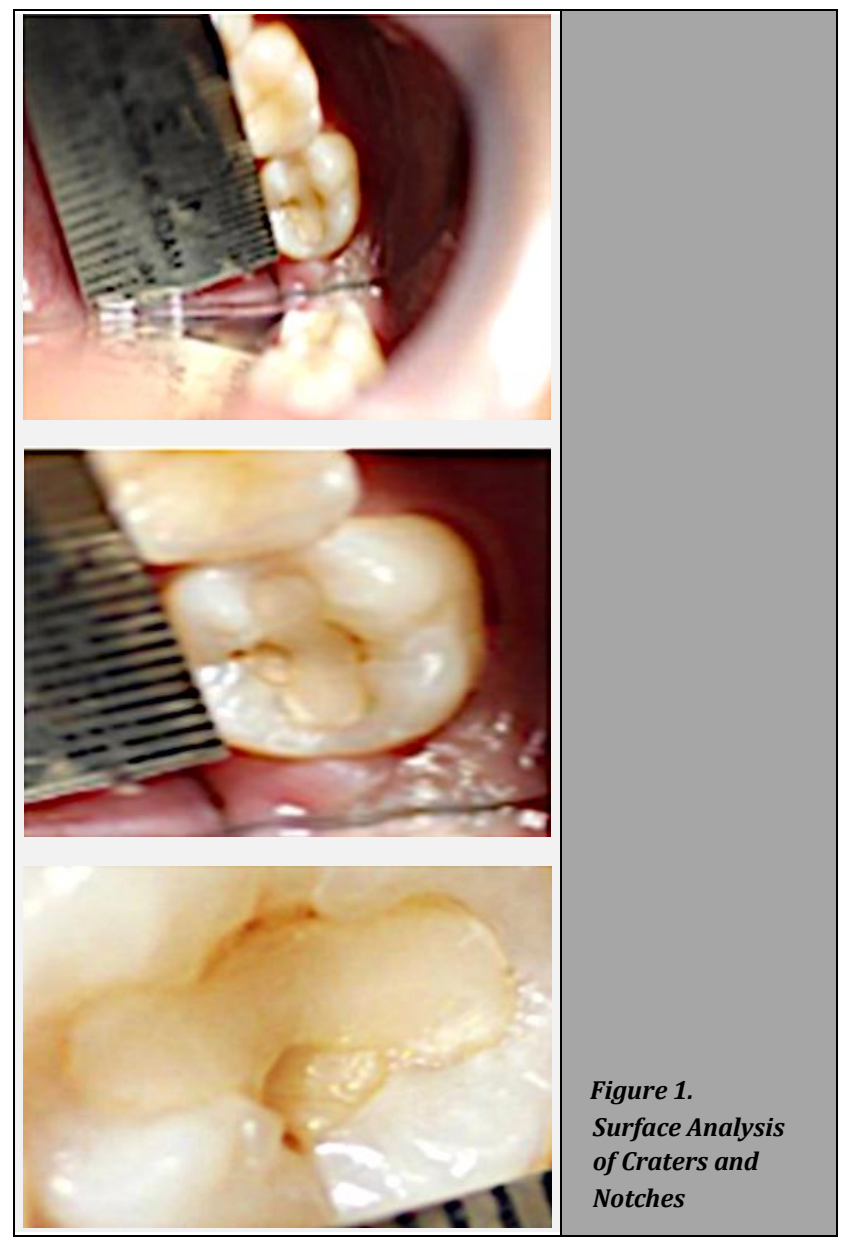

\begin{tabular}{|c|c|c|c|c|c|}
\hline & & $\mathbf{N}$ & Mean & S.D. & $\mathrm{P}$ \\
\hline \multirow{4}{*}{ Area } & 1 & 10 & 1551.931 & 384.296 & \\
\hline & 2 & 10 & 1902.029 & 669.630 & \\
\hline & 3 & 10 & 2117.122 & 447.860 & \\
\hline & Total & 30 & 1857.028 & 550.786 & 0.63 \\
\hline \multirow{4}{*}{ Mean } & 1 & 10 & 185.281 & 5.075 & \\
\hline & 2 & 10 & 187.950 & 9.189 & \\
\hline & 3 & 10 & 207.008 & 10.754 & \\
\hline & Total & 30 & 193.413 & 12.920 & 0.0005 \\
\hline \multirow{4}{*}{ Min } & 1 & 10 & 176.415 & 7.592 & \\
\hline & 2 & 10 & 181.747 & 7.113 & \\
\hline & 3 & 10 & 196.581 & 8.110 & \\
\hline & Total & 30 & 184.914 & 11.371 & 0.0005 \\
\hline \multirow{4}{*}{ Max } & 1 & 10 & 198.873 & 10.198 & \\
\hline & 2 & 10 & 210.898 & 5.929 & \\
\hline & 3 & 10 & 216.649 & 14.395 & \\
\hline & Total & 30 & 208.807 & 12.815 & 0.003 \\
\hline \multirow{4}{*}{ Angle } & 1 & 10 & 36.840 & 81.573 & \\
\hline & 2 & 10 & 44.195 & 90.997 & \\
\hline & 3 & 10 & 52.484 & 27.948 & \\
\hline & Total & 30 & 44.506 & 70.139 & 0.890 \\
\hline \multirow{4}{*}{ Length(micron) } & 1 & 10 & 90.116 & 28.546 & \\
\hline & 2 & 10 & 110.990 & 48.388 & \\
\hline & 3 & 10 & 127.566 & 30.843 & \\
\hline & Total & 30 & 109.557 & 38.957 & 0.95 \\
\hline
\end{tabular}

The mean and standard deviations of the area of tooth were assessed, and angle, length, maximum, minimum and mean diameters of craters are summarised in (Table 1). There was a significant increase in the mean, maximum and minimum diameters between three groups $(\mathrm{p}<0.05)$. No significant difference was observed between the area of the tooth assessed, length and angle of craters and notches between the three groups ( $p>0.05)$. (Table 1). Tukey's post hoc test results proved that, Group 3 showed significantly higher values compared to other groups.

\section{DISCUSSION}

All composite restorations showed a considerable wear on clinical service. Heavy restorations that are polished did not retain their polish after few years of clinical service. Attrition from the opposing restorations, created craters that varied widely in diameter and for the single tooth, the crater diameters varied greatly. Increased diameter and irregular shape patterns were observed on magnification. Varied values were obtained on statistical analysis. Higher values were seen for the teeth with longer clinical service. Mean and standard deviation was calculated. The entire surface area was analysed and highest values were taken into consideration for each single tooth.

In last two decades there were several major developments in the dental resin composites. ${ }^{10}$ Because of the regular improvements in the materials being so rapid, the long term clinical evaluation or clinical data on the materials is rarely available. ${ }^{10}$ Although in-vitro methods provide majority of the information on the potential performance and the handling characteristics, they cannot answer the questions on in-vivo longevity of tooth coloured restorations.6,10,11 Many clinicians used composite restorations, successfully in posterior stress bearing areas. ${ }^{12}$ However, they had inherent problems on usage of these composites for posterior restorations one of them are inadequate wear resistance, marginal leakage, secondary caries and lack of appropriate contact. 13

The definitive way of assessment of these materials is best obtained from the randomized controlled trails. ${ }^{14}$ Postoperative sensitivity seemed to be a problematic thing with the resin composite restorations and many studies have shown that following the placement, $30 \%$ of population has reported postoperative sensitivity with posterior composite restoration. ${ }^{15,16}$ Studies reveal the main two reasons for the replacement of posterior resin based composite restorations mainly due to the lack of marginal adaptation and the presence of secondary caries for the failure of restorations. ${ }^{16}$

The most important advantages of the composite restoratives are mainly the conservative tooth preparations being performed and the improved biomechanical characteristics of the material. ${ }^{17}$ Although it has many advantages the common concern with the usage of composites is mainly the wear when used to restore posterior teeth. ${ }^{1}$ The longevity of the posterior restorations is mainly dependent on various factors the major includes the material factors, patient and the dentist. ${ }^{18}$ Studies state that wear is one of the principal factors for the failure of the restoration. ${ }^{18}$ When compared with the longevity, amalgam shows better longevity and clinical service when compared to composites. ${ }^{19}$ Composites placed in larger cavities seem to show more marginal gaps, 
leading to micro-leakage and ultimately the failure of the restoration. ${ }^{19}$

The most frequent reason for the replacement of restorations is secondary caries followed by marginal degradation..$^{20}$ Resin based composites seem to fail more when compared to amalgam. ${ }^{20}$ Matrix type, shape, size, volume and distribution of filler particles, filler hardness, silanization and the degree of conversion (DC) are the factors that affect mostly the wear of composites. ${ }^{20,21}$ A smaller size of filler particles, more silanization and volume percentage of filler result in less composite wear. ${ }^{22,23}$ Composites with different monomers have different Degree of conversion have an effect on the wear resistance. ${ }^{24}$ Properties of restorations are also influenced by several factors like temperature changes, $\mathrm{pH}$ level, and the saliva, which ultimately affects the wear of the composites.

Although resin composites can bind to the tooth structure and seem to be aesthetic, they are not suitable for restoring the large defects. The acid resistance property is another criterion considered while selecting materials for restoring teeth. Previous studies have shown that some dietary foods and beverages that are chemically acidic can cause surface degradation of restorative materials. ${ }^{25}$ These acidic foods and beverages can alter the surface hardness, but cause only minor changes to the resin composite. ${ }^{25}$ The performance of all restorations is dependent on the biodynamic environment of the oral cavity. The resin composite should be polished after polymerization because rough, unpolished restorations, increases the coefficient of friction and may increase the rate of wear. ${ }^{26}$ After polymerization, the resin matrix and filler particles have different levels of hardness that cause variations in polishing efficiency. ${ }^{27}$ This variability can lead to differences in surface roughness. Because of composition diversity, various resin composites exhibit different levels of surface roughness after polishing. ${ }^{27}$ Materials with fillers of larger sizes generally show more surface roughness ${ }^{28}$ and increased voids ${ }^{29}$ than those with fillers of smaller sizes. Properties of the materials and the technical approaches are the two important aspects, which play an important role in the clinical performance of the composite restorations. ${ }^{30}$

There have been several modifications in the organic matrix and the filler particles for the better usage of composites as posterior restorations. ${ }^{30}$ larger surface area of the particles with reduced filler size result in more water uptake, ultimately leading to the degradation of the material, which may finally affect the dynamic mechanical properties of the material on long run. As fillers are incorporated into the organic matrix by a chemical treatment of their surfaces, this interface can be stressed and be loosened from the matrix in different patterns, through a three- body abrasive action and tooth brushing which provokes a mechanical challenge. In consequence, these particles can be loosed, fractured or the organic matrix can be removed, exposing the particles. Thus, roughness and wear can lead to the ultimate failure of the restoration. Hence, mechanical properties are of great interest to allow composite resins to be well indicated..$^{30}$ Filler particles play an important role in this mechanism. ${ }^{31}$ they are responsible for the strength of the material and also protect organic matrix from wear. ${ }^{30}$ Organic matrix is the second point of interest to be focused. There have been several investigations with the purpose to promote modifications to reach better properties. ${ }^{31}$ thus, balance between the organic matrix and fillers are responsible for the long-term clinical success of the restoration. Different finishing and polishing methods also have a role in altering the surface roughness, micro hardness and marginal sealing of the restoration. Considering this fact, study by Ece Eden et al.,32 proved, one step polishing systems to be better as compared to multistep system for polishing resin composite restorations. The light curing type and irradiance also plays an important role in altering the surface property of polymerised resin composite restoration. The resin composites polymerised using lowest irradiance level, showed to have enough micro hardness as compared with one's cured at higher irradiation levels. ${ }^{33}$

Therefore, comparison of the performance of resin-based materials is an essential parameter to aid clinical indication of the long-term success of the restoration. ${ }^{34}$ When done properly a composite restoration provides excellent service for years. This study laid a unique perspective in evaluating the performance of restorative materials in clinical service. The major limitation of the study is that operator is unaware of the type or brand of composite material used, which also have an impact on the wear resistance of the restorations placed.

\section{CONCLUSIONS}

Despite of many improvements in the composites, wear resistance still has to be improved. This study was conducted in a local population, as the dietary habits vary with in a specific population. Although this study proved that the wear of restoration increased on increased clinical duration and was influenced by the dietary habits of patients.

Financial or Other Competing Interests: None.

\section{REFERENCES}

[1] Chan KHS, Mai Y, Kim H, et al. Review: resin composite filling. Materials (Basel) 2010;3(2):1228-43.

[2] Ritter AV. Posterior composites revisited. J Esthet Restor Dent 2008;20(1):57-67.

[3] Lynch CD, Frazier KB, McConnell RJ, et a. State-of-the-art techniques in operative dentistry: contemporary teaching of posterior composites in UK and Irish dental schools. Br Dent J 2010;209(3):129-36.

[4] Ferracane JL. Is the wear of dental composites still a clinical concern? Is there still a need for in vitro wear simulating devices? Dent Mater 2006;22(8):689-92.

[5] Opdam NJM, van de Sande FH, Bronkhorst E, et al. Longevity of posterior composite restorations : a systematic review and meta-analysis. J Dent Res 2014;93(10):943-9.

[6] Cao L, Zhao X, Gong X, et al. An invitro investigation of wear resistance and hardness of composite resins. Int J Clin Exp Med 2013;6(6):423-30.

[7] Duboust N, Ghadbeigi H, Pinna C, et al. An optical method for measuring surface roughness of machined carbon fibre-reinforced plastic composites. J Compos Mater 2017;51(3):289-302.

[8] de Oliveria GU, Mondelli RFL, Rodrigues MC, et al. Impact of filler size and distribution on roughness and wear of 
composite resin after simulated toothbrushing. J Appl Oral Sci 2012;20(5):510-6.

[9] Patel MU, Punia SK, Bhat $S$, et al. An in vitro evaluation of microleakage of posterior teeth restored with amalgam, composite and zirconomer - a stereomicroscopic study. J Clin Diagn Res 2015;9(7):ZC65-7.

[10] Celik C, Arhun N, Yamanel K. Clinical evaluation of resinbased composites in posterior restorations: 12-month results. Eur J Dent 2010;4(1):57-65.

[11] Efes BG, Dörter C, Gömeç Y. Clinical evaluation of an ormocer, a nanofill composite and a hybrid composite at 2 years. Am J Dent 2006;19(4):236-40.

[12] Gerbo L, Leinfelder KF, Mueninghoff L, et al. Use of optical standards for determining wear of posterior composite resins. J Esthet Dent 1990;2(5):148-52.

[13] Leinfelder KF. Posterior composite resins: the materials and tiger clinical performance. J Am Dent Assoc 1995;126(5):663-6.

[14] Fagundes TC, Barata TJE, Bresciani E, et al. Clinical evaluation of two packable posterior composites: 2-year follow-up. Clin Oral Investig 2006;10(3):197-203.

[15] Stangel I, Barolet RY. Clinical evaluation of two posterior composite resins: two-year results. J Oral Rehabil 1990;17(3):257-68.

[16] Letzel H. Survival rates and reasons for failure of posterior composite restorations in multicentre clinical trial. J Dent 1989;17 Suppl 1:S10-7.

[17] Cetin AR, Unlu N. One-year clinical evaluation of direct nanofilled and indirect composite restorations in posterior teeth. Dent Mater J 2009;28(5):620-6.

[18] Hickel R, Manhart J. Longevity of restorations in posterior teeth and reasons for failure. J Adhes Dent 2001;3(1):4564.

[19] Roulet JF. Benefits and disadvantages of tooth-coloured alternatives to amalgam. J Dent 1997;25(6):459-73.

[20] Turssi CP, De Moraes Purquerio B, Serra MC. Wear of dental resin composites: insights into underlying processes and assessment methods--a review. J Biomed Mater Res B Appl Biomater 2003;65(2):280-5.

[21] Nagarajan VS, Jahanmir S, Thompson VP. In vitro contact wear of dental composites. Dent Mater 2004;20(1):63-71.
[22] Johnsen GF, Taxt-Lamolle SF, Haugen HJ. Wear model simulating clinical abrasion on composite filling materials. Dent Mater J 2011;30(5):739-48.

[23] Lim BS, Ferracane JL, Condon JR, et al. Effect of filler fraction and filler surface treatment on wear of microfilled composites. Dent Mater 2002;18(1):1-11.

[24] Turssi CP, Faraoni-Romano JJ, de Menezes M, et al. Comparative study of the wear behavior of composites for posterior restorations. J Mater Sci Mater Med 2007;18(1):143-7.

[25] Wongkhantee S, Patanapiradej V, Maneenut C, et al. Effect of acidic food and drinks on surface hardness of enamel, dentine, and tooth-coloured filling materials. J Dent 2006;34(3):214-20.

[26] Krejci I, Lutz F, Boretti R. Resin composite polishing-filling the gaps. Quintessence Int 1999;30(7):490-5.

[27] Yap AU, Lye KW, Sau CW. Surface characteristics of toothcolored restoratives polished utilizing different polishing systems. Oper Dent 1997;22(6):260-5.

[28] Tjan AH, Chan CA. The polishability of posterior composites. J Prosthet Dent 1989;61(2):138-46.

[29] Elbishari H, Silikas N, Satterthwaite J. The effect of filler size on the presence of voids within resin composite. J Int Dent Med Res 2018;11(2):409-13.

[30] Ilie N, Hickel R. Investigations on mechanical behaviour of dental composites. Clin Oral Investig 2009;13(4):427-38.

[31] 0'Brien WJ, Yee J. Microstructure of posterior restorations of composite resin after clinical wear. Oper Dent 1980;5(3):90-4.

[32] Eden E, Cogulu D, Attin T. The effect of finishing and polishing systems on surface roughness, microhardness and microleakage of a Nanohybrid composite. J Int Dent Med Res 2012;5(3):155-60.

[33] Indrani DJ, Damiyanti M, Udhiarto A. Effects of different irradiance levels of the light curing unit on the dental resin composite's microhardness and cytotoxicity. J Int Dent Med Res 2019;12(1):138-42.

[34] Taumihardja M, Andries S, Yongki R. Polymerisation of resin-based composites restoration: a literature review. J Int Dent Med Res 2019;12(4):1618-25. 